
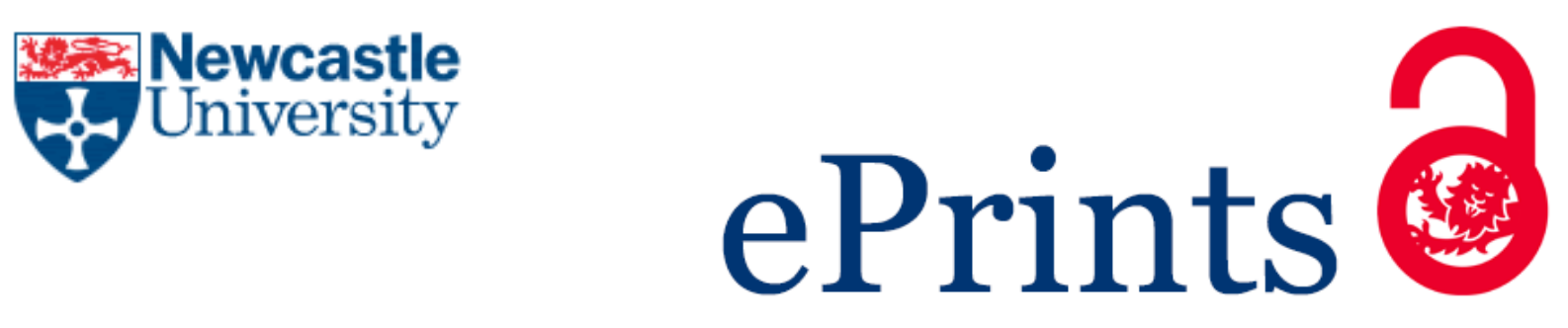

\author{
Stephen AO, Dalgarno KW, Munguia J. \\ Process control testing for fused filament fabrication. \\ Rapid Prototyping Journal 2017, 23(2) \\ DOI: http://dx.doi.org/10.1108/RPJ-07-2015-0084
}

\title{
Copyright:
}

This is the authors' accepted manuscript of an article that has been published in its final definitive form by Emerald Publishing Limited, 2017.

DOI link to article:

http://dx.doi.org/10.1108/RPJ-07-2015-0084

Date deposited:

$24 / 02 / 2017$

Embargo release date:

20 March 2018 


\section{Process control testing for fused filament fabrication}

\begin{tabular}{|r|l|}
\hline Journal: & Rapid Prototyping Journal \\
\hline Manuscript ID & RPJ-07-2015-0084.R1 \\
\hline Manuscript Type: & Original Article \\
\hline Keywords: & Fused filament fabrication, 3D printing, Polylactic acid, Quality assurance \\
\hline \multicolumn{2}{|c}{} \\
\hline
\end{tabular}

\section{SCHOLARONE \\ Manuscripts}




\title{
Process control testing for fused filament fabrication
}

\begin{abstract}
The aim of this research is to determine what tests can be most useful in quality assurance and control when using Fused Filament Fabrication (FFF) 3D printing machines. The quality of the bond between layers is critical to the structural integrity of FFF fabricated parts. Therefore, to determine the influence of process parameters on quality of parts tensile, flexural, notched and un-notched impact test specimens were fabricated in polylactic acid (PLA) using FFF with different layer thicknesses, fill densities, orientation and print speeds. The mechanical properties were then assessed along with the accuracy and mass of the samples. It is concluded that a notched impact test gives a measure of interlayer bond strength which can be used across build styles in order to track machine performance, and that this together with the mass and dimensions of the impact-test specimens offers an appropriate set of tests capable of tracking the mechanical properties of parts produced using the FFF technique. Therefore, this research finding will be of value in benchmarking FFF machines for quality parts fabrications.
\end{abstract}

Keywords: Fused filament fabrication, Quality assurance, Polylactic acid, 3D printing 


\section{Introduction}

Fused filament fabrication (FFF) is an additive manufacturing (AM) process that builds 3D physical parts by extrusion of melted polymer filaments. FFF is one of the most important AM processes because of the ease of operation and low cost of machinery (Levy et al., 2003; Rosochowski and Matuszak, 2000).

An FFF machine (see Figure 1) consists of an extruder head with heated nozzle for depositing plastic filaments, typically of diameter 1.75 or $3 \mathrm{~mm}$. Some machines have a single nozzle while others have multiple nozzles (normally two: one for depositing part material and the other for support material). The tool path of the extruder head is based on computer numerical control system which enables material to be deposited in a precise pattern on the platform and also controls movement of the platform.

The process involves the movement of filaments from the filament reels through a system of rollers into the extruder head where it is heated to a molten state and then deposited onto the movable platform. The deposited material (called a "road” (Ahn et al., 2002), see Figure 2) then cools and solidifies. On completion of deposition of a layer the platform will move downward (in the $\mathrm{Z}$ - direction) so that another layer can be bonded on top of the previous layer. This process of stacking and joining continues until the part is complete.

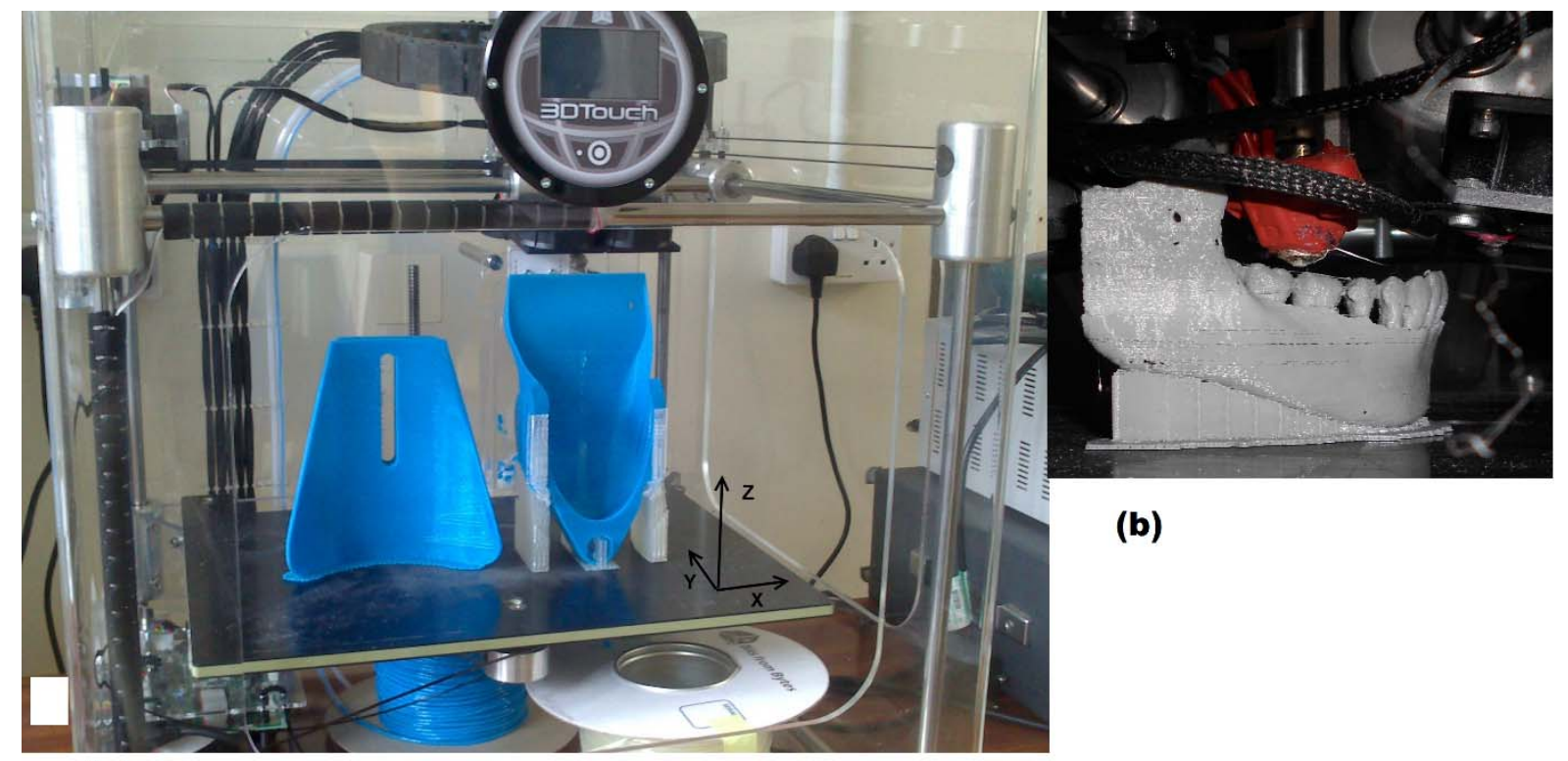

(a)

Figure 1 (a) 3D Touch FFF machine; (b) extruder head depositing material 


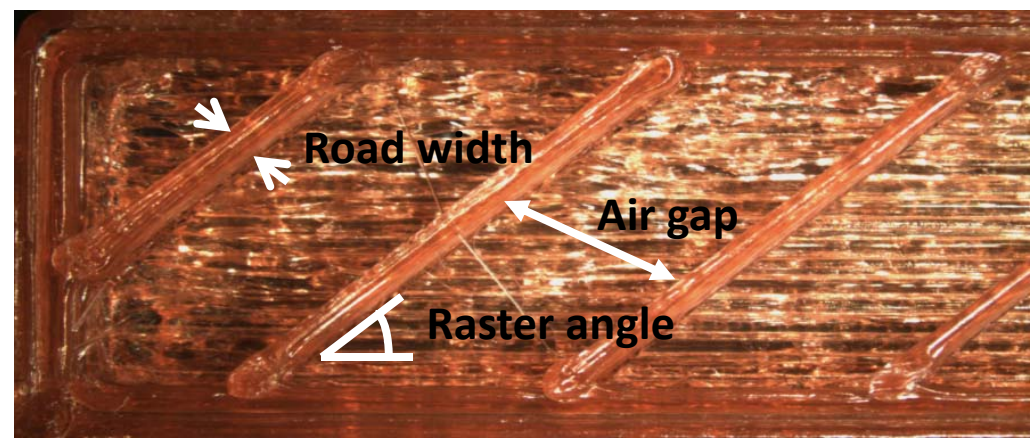

Figure 2 Definition of road width, air gaps and raster angle

The need for FFF parts to have reliable mechanical properties, dimensional accuracy and surface finish (Sun et al., 2008; Anitha et al., 2001; Ahn et al., 2002) has been identified. Several studies have assessed the effect of process parameters on the mechanical properties, accuracy and surface roughness of fabricated parts in FFF machines, and these are summarised in Table 1. 
Table 1 Effect of process parameters on products made by FFF process

\begin{tabular}{|c|c|c|}
\hline Publication & Process parameters studied & Conclusion \\
\hline $\begin{array}{l}\text { Pandey et al. (2003b) } \\
\text { Vasudevarao et al. (2000) }\end{array}$ & Orientations of part, layer thickness & $\begin{array}{l}\text { The surface roughness was found to be affected by staircase } \\
\text { effect, layer thickness and part orientations }\end{array}$ \\
\hline $\begin{array}{l}\text { Anitha et al. (2001) } \\
\text { Peng et al. (2014) }\end{array}$ & $\begin{array}{l}\text { Road width, build layer thickness and speed of } \\
\text { deposition }\end{array}$ & $\begin{array}{l}\text { Surface roughness and dimensional accuracy are affected by } \\
\text { those parameters. }\end{array}$ \\
\hline Pandey et al. (2003a) & $\begin{array}{l}\text { Slicing of layer edge profile for fused deposition } \\
\text { modelling and layer thickness }\end{array}$ & $\begin{array}{l}\text { Geometrical inaccuracies and surface finish are affected by } \\
\text { layer thickness. But minimizing the layer thickness leads to } \\
\text { maximization of the build time. }\end{array}$ \\
\hline Agarwala et al. (1996) & $\begin{array}{l}\text { Filament quality, build temperature, feed roller } \\
\text { speed, flow rate and fill pattern }\end{array}$ & Structural quality of part is affected by those parameters \\
\hline $\begin{array}{l}\text { Lee et al. ( 2005) } \\
\text { Sood et al. (2009 and 2010) } \\
\text { Chang and Huang (2011) } \\
\text { Equbal et al. (2010); Masood et al. (2010) }\end{array}$ & $\begin{array}{l}\text { Raster angle, raster width and layer thickness, air } \\
\text { gap and part orientation }\end{array}$ & $\begin{array}{l}\text { The parameters affect elastic performance, dimensional } \\
\text { accuracy, surface finish and strength }\end{array}$ \\
\hline $\begin{array}{l}\text { Sun et al. (2008) } \\
\text { Zhang and Chou (2006); Qui and Langrana } \\
\text { (2002); Qui et al. (2001) }\end{array}$ & $\begin{array}{l}\text { Heat transfer in building chamber, road width and } \\
\text { tool path pattern }\end{array}$ & $\begin{array}{l}\text { The quality of bond is affected by heat transfer, distortion } \\
\text { and tool path }\end{array}$ \\
\hline Ang et al. (2006); Ahn et al. (2002) & $\begin{array}{l}\text { Air gap and raster width, raster orientation, } \\
\text { colour and model temperature }\end{array}$ & $\begin{array}{l}\text { Mechanical properties are affected by porosities due to those } \\
\text { parameters, model colour and temperature have little effect }\end{array}$ \\
\hline Sophia et. al (2015) & Raster orientation & $\begin{array}{l}\text { Tensile and fatigue properties are affected by raster } \\
\text { orientation }\end{array}$ \\
\hline
\end{tabular}


The main parameters of interest as observed from Table 1 are dimensional accuracy and mechanical properties, which Table 1 also indicates to be highly dependent on processing parameters and the state of the machine at any point in time. There is a need for well-defined methods for checking the quality of parts that are made using the process to ensure the reliability of those parts. The research reported in this paper has been directed towards developing a rational set of tests for monitoring the quality of FFF made parts in order to assure the quality of the fabricated parts. Since quality assurance (QA) involves resources, there is a need to ensure that QA tests are effective, reliable, cheap and capable of being carried out quickly.

\section{Materials and methods}

\subsection{Experimental Approach}

The approach taken has been to identify a set of impact (notched and un-notched), tensile and flexural specimens, and to manufacture these using a range of processing conditions, in order to retrospectively assess the ability of the different test techniques to provide measurements which were good indicators of mechanical integrity and dimensional accuracy. Sample mass was also recorded. The specimens were all manufactured using a Bits from Bytes (BFB) 3D Touch FFF machine, using 3 mm diameter PLA filament, also sourced from Bits from Bytes.

\subsubsection{Test Specimens}

Figure 3 shows the shape and dimensions of test specimens. Tensile test specimens were made according to BS EN ISO 527 method 1A (BS EN ISO 527-1:1996) (Figure 3b). Flexural test samples (Figure 3c) were made according to BS EN ISO 178 (BS EN ISO 178:2010). Both tensile and flexural tests were conducted using an Instron 4505 electromechanical system at a crosshead speed of $2 \mathrm{~mm} / \mathrm{min}$, with the arrangement of the flexural test shown in Figure 3d. The flexural strength $\left(\sigma_{f}\right)$ and flexural modulus $\left(E_{f}\right)$ for stress/strain behaviour in three - point bending test for a rectangular beam is calculated from;

$$
\begin{aligned}
\sigma_{f} & =3 F L / 2 b h^{2} \\
E_{f} & =\left(L^{3} / 4 b h^{3}\right)(\Delta F / \Delta S)
\end{aligned}
$$

Where, $F$ is the highest recorded applied force at centre of beam, $L$ is the span, $b$ is the specimen width, $h$ is the specimen thickness, and $(\Delta F / \Delta S)$ is the slope between the applied force $(F)$ and deflection $(S)$ in the linear elastic portion of the curve. 


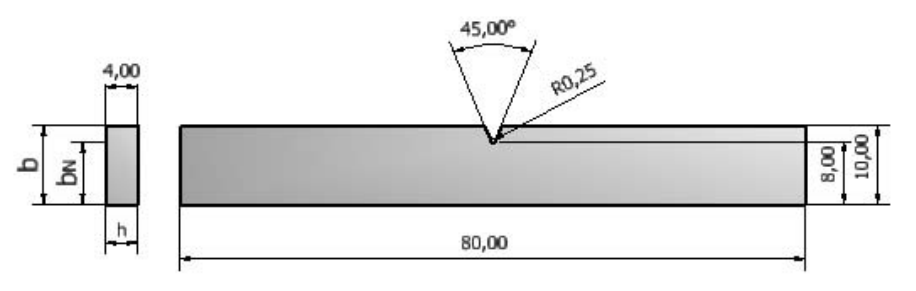

(a)

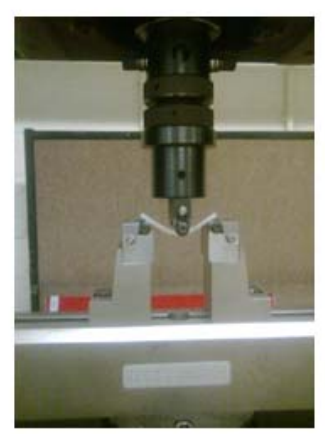

(d)

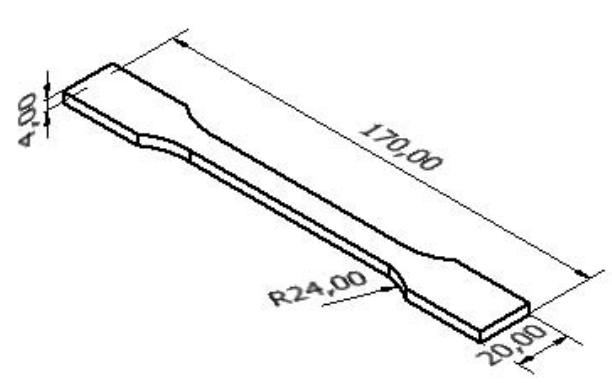

(b)

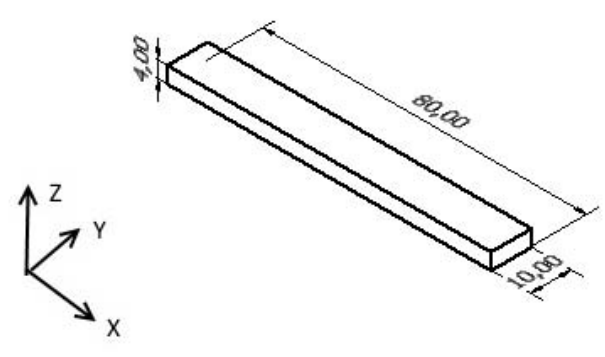

(c)

Figure 3- Test specimens; (a) Notched impact; (b) Tensile; (c) Flexural and un-notched impact (all dimensions are in $\mathrm{mm}$ ) and; (d) flexural specimen under load

Impact test specimens were made according to BS EN ISO 180 (BS EN ISO 180:2001)

(Figure 3b). All the impact tests were carried out using a Digital Pendulum Impact tester with pendulum capacity of $22 \mathrm{~J}$. The impact strength was then calculated using equations 2 and 3 for notched and un-notched specimen respectively:

$$
\begin{gathered}
E_{i}=\left(E /\left(h \times b_{N}\right)\right) \times 10^{3} \\
E_{i}=(E /(h \times b)) \times 10^{3}
\end{gathered}
$$

Where $E_{i}$ is the impact strength, $E$ is the measured impact energy, h is the thickness, $\mathrm{b}$ is the width and $b_{N}$ is the remaining width under the notch of the test specimens (as shown in Figure 3).

\subsubsection{Manufacture}

Four different sets of processing parameters were used to make the parts, as shown in Table 2 below. The parameters which were varied were print speed, layer thickness, and fill density.

Specimens were made in different built orientation in the FFF machine. The orientation is the angular positioning of parts in the build chamber in reference to $\mathrm{X}, \mathrm{Y}$, and $\mathrm{Z}$ axes where $\mathrm{XY}$ 
plane is parallel to the build table, and there $\mathrm{Z}$ - axis is perpendicular to the table (as shown in Figure 1a). Print speed is the linear speed of movement of the extrusion head in the XY plane. For this specific machine a "speed multiplier" is used to increase or decrease the speed of the nozzle relative to a speed of approximately $16 \mathrm{~mm} / \mathrm{s}(1 \mathrm{X})$. Speed multipliers of $1 \mathrm{X}$ and 1.3X ( $21.33 \mathrm{~mm} / \mathrm{s})$ were used in this study. The print speed of $16 \mathrm{~mm} / \mathrm{s}$ was the recommended print speed for this machine/material combination, and the $1.3 \mathrm{X}$ multiplier was selected as the maximum speed which the control software (Axon 2.0) allowed. Initial testing showed that the $1.3 \mathrm{X}$ print speed produced consistently successful builds. Layer thickness is the thickness of deposited layer.

Typically layers are deposited using a "skin/core" approach. The outer perimeter of a layer is defined by extruding a number of continuous roads of material to define the "skin". The area inside the skin is known as the "core" and is then filled by extruding material. To save on material and build time the fill pattern is commonly less than $100 \%$ dense, and a variety of fill patterns can be used. The fill density is the nominal density with which material will be deposited in the core region of a layer. In this study two nominal fill densities of $20 \%$ and $100 \%$ were used. Figure 4 shows the extruder paths which these nominal values produced for each layer of the flexural test parts, as derived from the G-code which the BFB machine produced, and shows that because the parts were not much thicker than the wall thickness that the difference between the two fill densities was smaller than the nominal percentages would imply. This effect was also evident in tensile and impact specimens.

Specimens oriented along the Z-axis have been shown to have the lowest mechanical properties when load is applied perpendicularly to the layers (Bellini and Güçeri, 2003; Bagsik et al., 2010; Sood et al., 2010; Es-Said et al., 2000; Munguia et al., 2014). Zorientation of specimens was thus expected to be the worst case for evaluating interlayer bond strengths. Forty five ISO designed specimens (see Table 2) with five each oriented in $\mathrm{X}$-, Y- and Z-orientations were made with $100 \%$ fill density (process parameter set G2) to assess the variation of mechanical properties with build orientations. Initial testing indicated that five specimens per test condition was a practical number to gain an indication of the variation of properties. Eighty Z-oriented ISO designed specimens were made with the parameter set in Table 3. 
Table 2 ISO designed specimens with five each oriented in X-, Y-and Z-orientations

\begin{tabular}{ccccc}
\hline Test types & Tensile & Flexural & Notched Impact & Orientation \\
\hline No of specimens & 5 & 5 & 5 & $\mathrm{X}$ \\
5 & 5 & 5 & $\mathrm{Y}$ \\
5 & 5 & 5 & $\mathrm{Z}$ \\
\hline
\end{tabular}

Table 3 Specimens parameter sets

\begin{tabular}{lllll}
\hline Parameter sets & F1 & F2 & G1 & G2 \\
\hline Layer thickness (mm) & 0.5 & 0.5 & 0.25 & 0.25 \\
Fill density (\%) & 20 & 100 & 20 & 100 \\
Speed multiplier & $1 \mathrm{X}$ & $1.3 \mathrm{X}$ & $1 \mathrm{X}$ & $1.3 \mathrm{X}$ \\
\hline
\end{tabular}

(a)

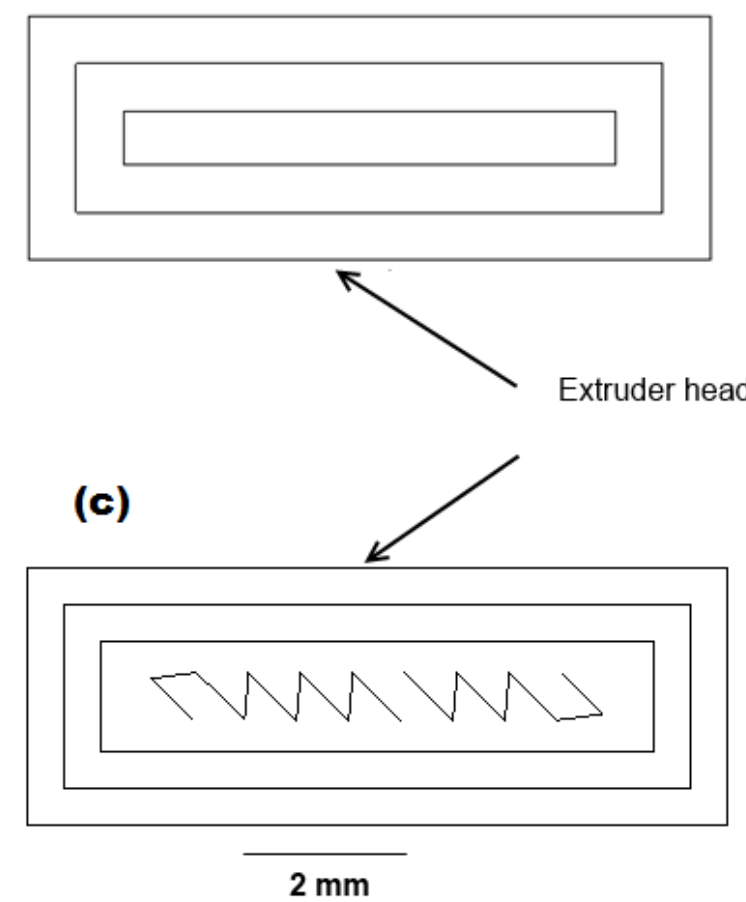

(b)

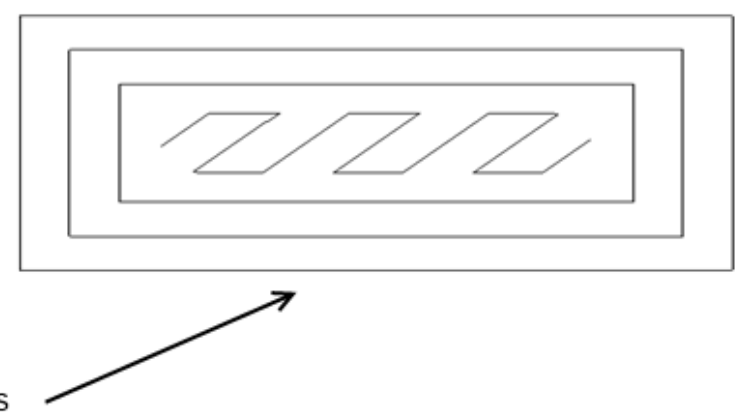

(d)

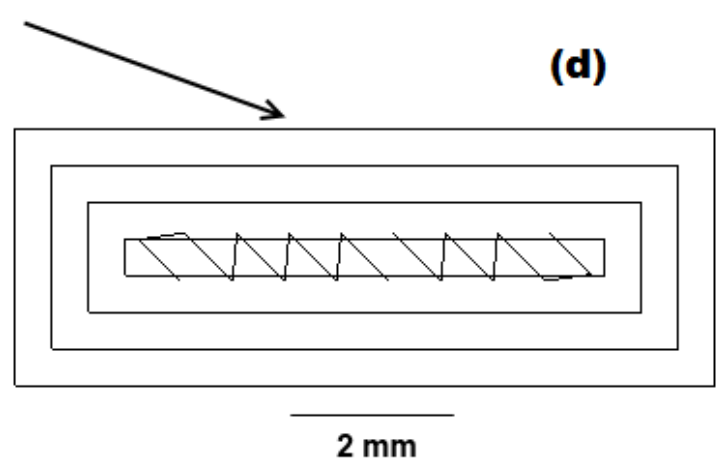

Figure 4 The build strategy with process parameter sets (a) F1; (b) F2; (c) G1; (d) G2 for flexural test parts made with those parameter sets 


\subsection{Experimental procedures}

\subsubsection{Specimens preparation and microscopic examination}

A Buehler Isomet 5000 was used to section specimens for microscopic examination, followed by cleaning in water in an ultrasonic bath. Thereafter, the internal structures of the specimens were then observed using a Nikon SMZ 1500 optical microscope.

\subsubsection{Determination of mass of specimens}

The mass of flexural, tensile and impact specimens was determine by weighing the fabricated specimens before test with a precision weighing balance (KERN PFB 200-3) with division size of $0.001 \mathrm{~g}$ and accuracy $+/-0.1 \%$.

\subsubsection{Dimensional accuracy}

The height, length and width of the flexural specimens were measured using a Mitutoyo Digital Calliper with a resolution of $0.01 \mathrm{~mm}$ and accuracy of $\pm 0.03 \mathrm{~mm}$, and then compared with the dimensions in Figure 3 to determine the dimensional accuracy.

\section{RESULTS}

\subsection{Variation of flexural and tensile strengths with build orientation}

Figure 5 shows the variation of tensile, flexural and notched impact strengths of specimens made with 100\% fill density (process parameter G2) and build orientation. In all cases the strength of parts made in the Z-orientation was significantly lower (to a 95\% confidence level) than that of those made in $\mathrm{X}$ and $\mathrm{Y}$. For tensile and flexural strength $\mathrm{Y}$-oriented parts showed the highest strength, with no significant difference in notched impact strength between $\mathrm{X}$ and $\mathrm{Y}$. 

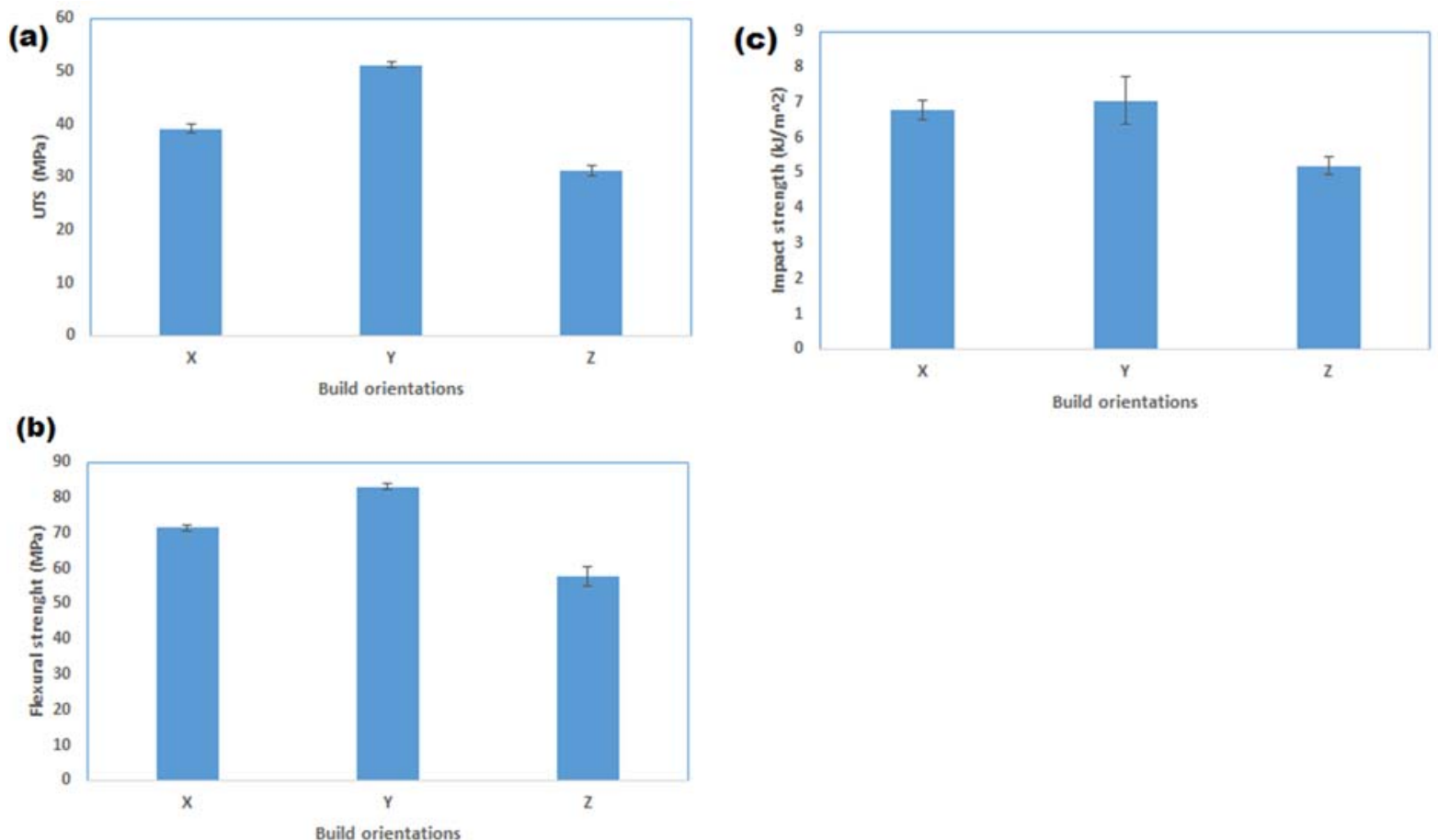

Figure 5 Variation of (a) tensile; (b) flexural, and (c) impact strength of FFF made PLA parts with build orientation. Errors bars indicate 95\% confidence intervals, $n=5$.

\subsection{Influence of Build Parameters on mass of test specimens}

Figure 6 and Figure 7 show the variation of sample mass of flexural, tensile, and notched and un-notched impact specimens, all made in the Z-orientation. It is clear that G samples are on average heavier than the equivalent $F$ samples, and that 2 samples are on average heavier than the equivalent 1 samples. 
(a)

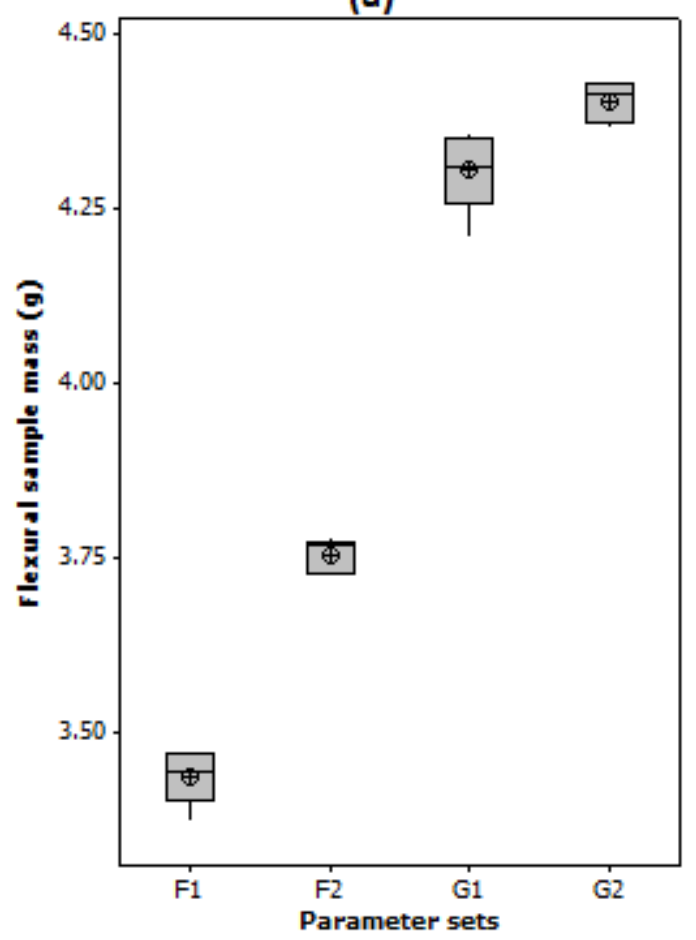

(b)

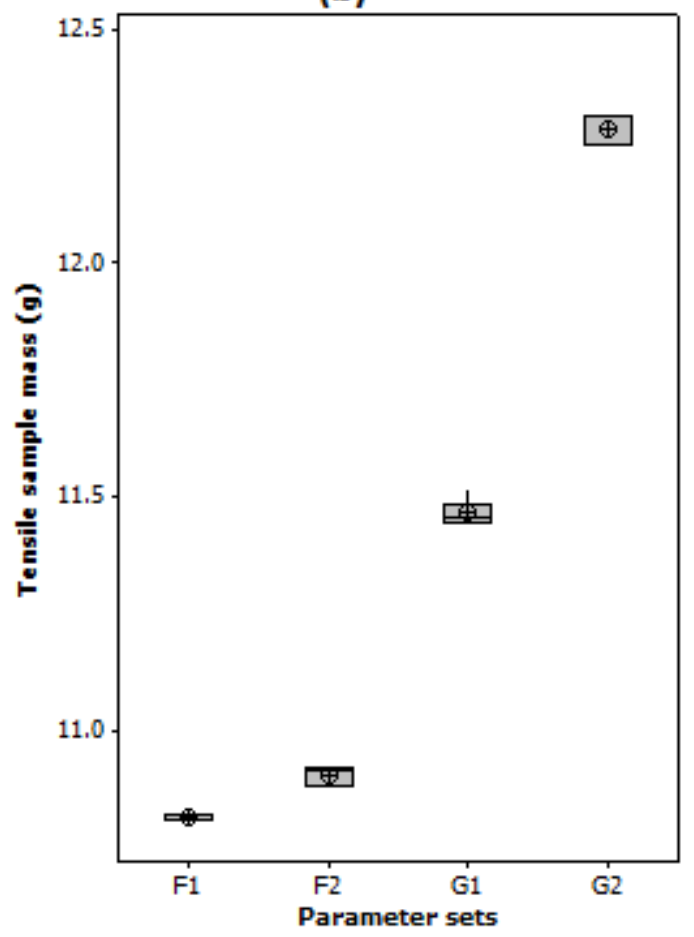

Figure 6 Mass of (a) flexural, and (b) tensile specimens with parameter sets, showing the mean, median, lower and upper limits, first and third quartile. Z oriented parts.

(a)

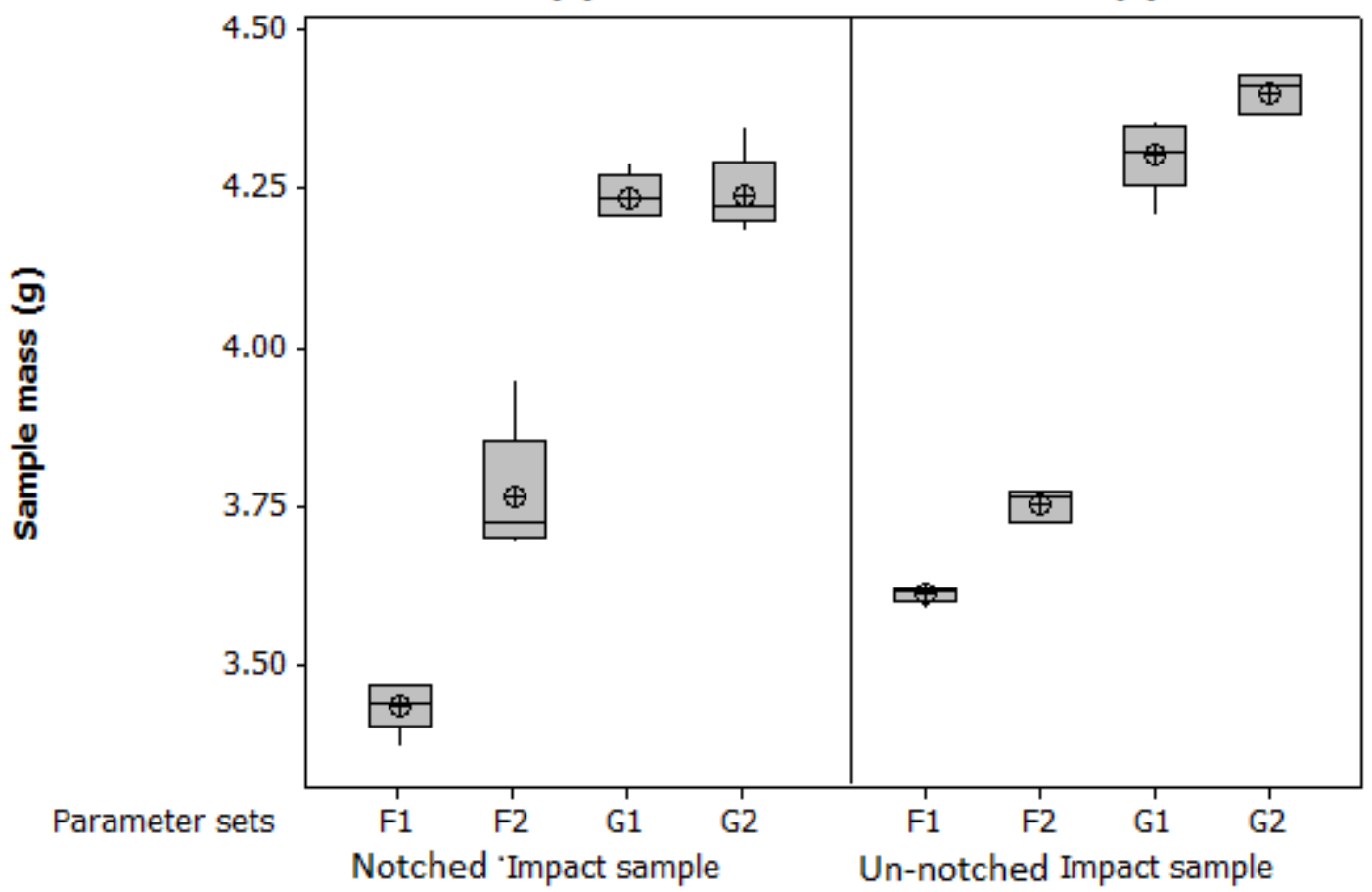

Figure 7 Mass of (a) notched and (b) un-notched impact specimens with parameter sets, showing the mean, median, lower and upper limits, first and third quartile. $\mathrm{Z}$ oriented parts. 


\subsection{Influence of Build Parameters on dimensional accuracy}

Figure 8 shows the variation of dimensional accuracies of length, width and thickness with parameter sets of parts made in the $\mathrm{Z}$ orientation. Whilst the thickness of parts was on average the least accurate of the dimensions, there is no significant difference between the parameter sets.

(a)

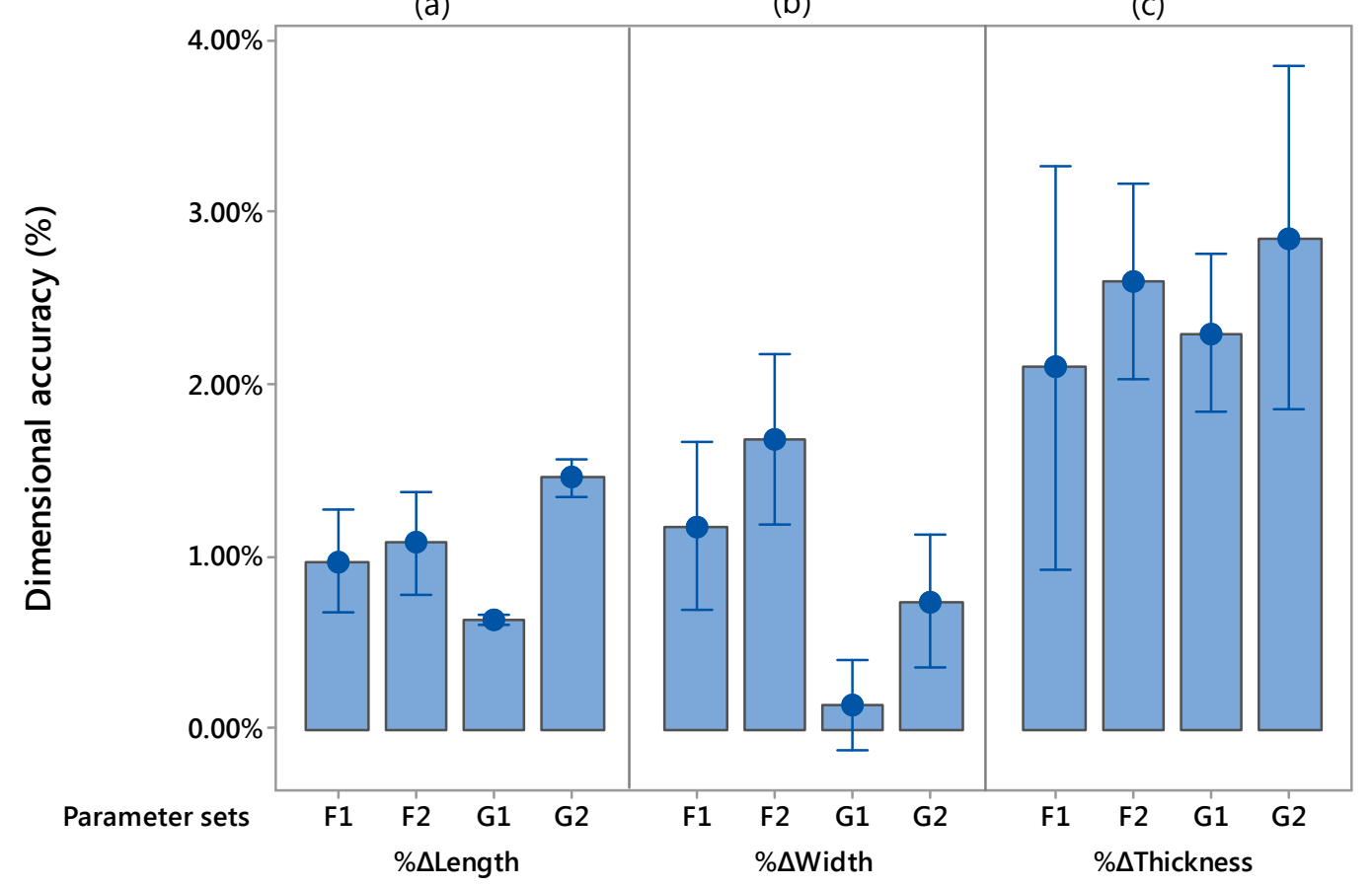

Figure 8 Variation of dimensional accuracy: (a) length; (b) width, and (c) thickness with parameter sets. $Z$ oriented parts. Errors bars indicate $95 \%$ confidence intervals, $n=5$.

\subsection{Influence of Build Parameters on Strength}

Figure 9 shows the variation of tensile and flexural strengths with parameter sets, with both showing a similar trend: $\mathrm{G}$ samples are on average stronger than the equivalent $\mathrm{F}$ samples, and that 2 samples are on average stronger than the equivalent 1 samples. 

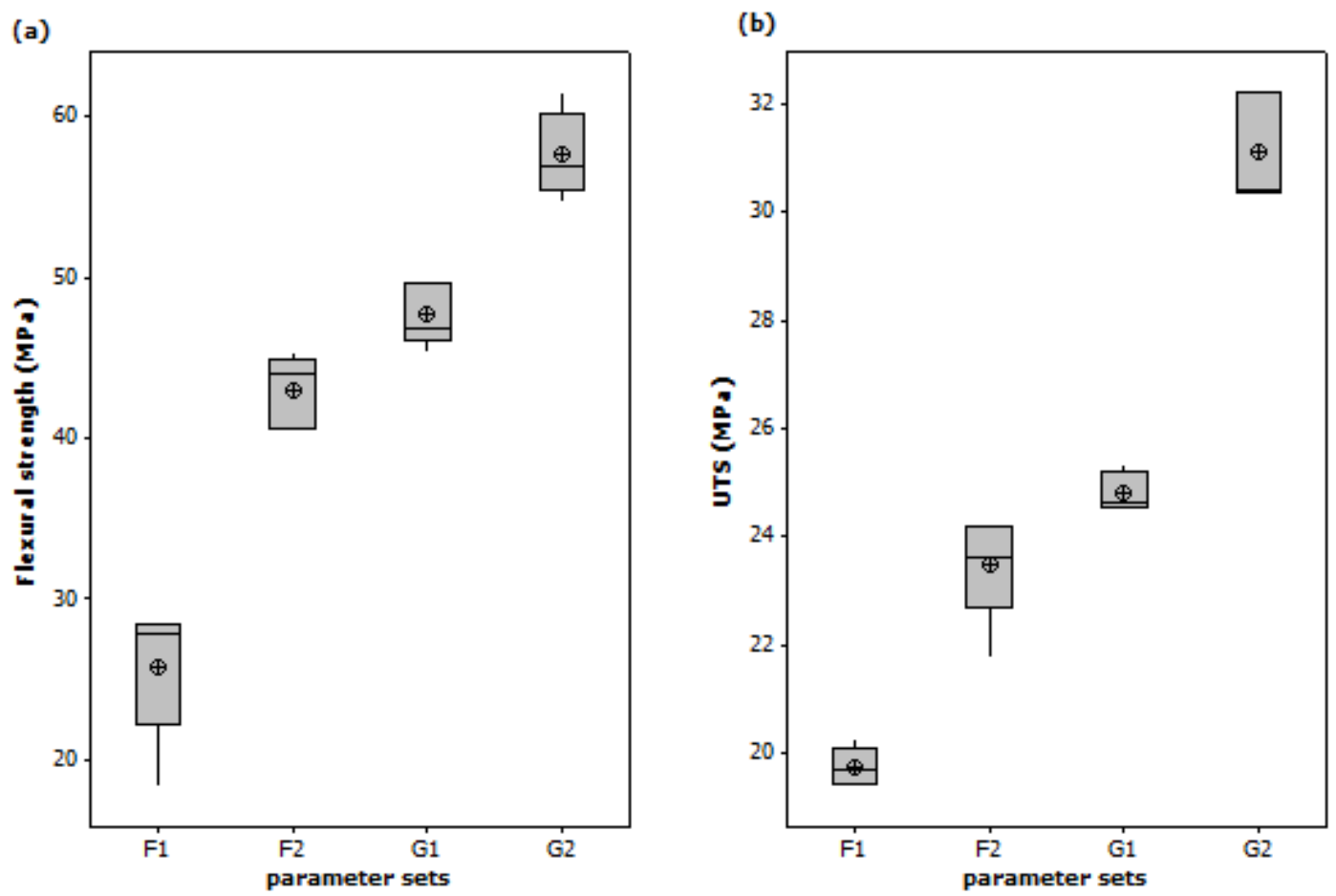

Figure 9 Variation of (a) flexural, and (b) tensile strengths with parameter sets, showing the mean, median, lower and upper limits, first and third quartile. $\mathrm{Z}$ oriented parts.

Figure 10 shows the variation of notched and un-notched impact strengths of Z- oriented specimens with parameter sets. This shows a similar trend to the tensile and flexural test results, but with a markedly different sensitivity: the results from the notched samples are much more closely grouped than those from the un-notched samples.

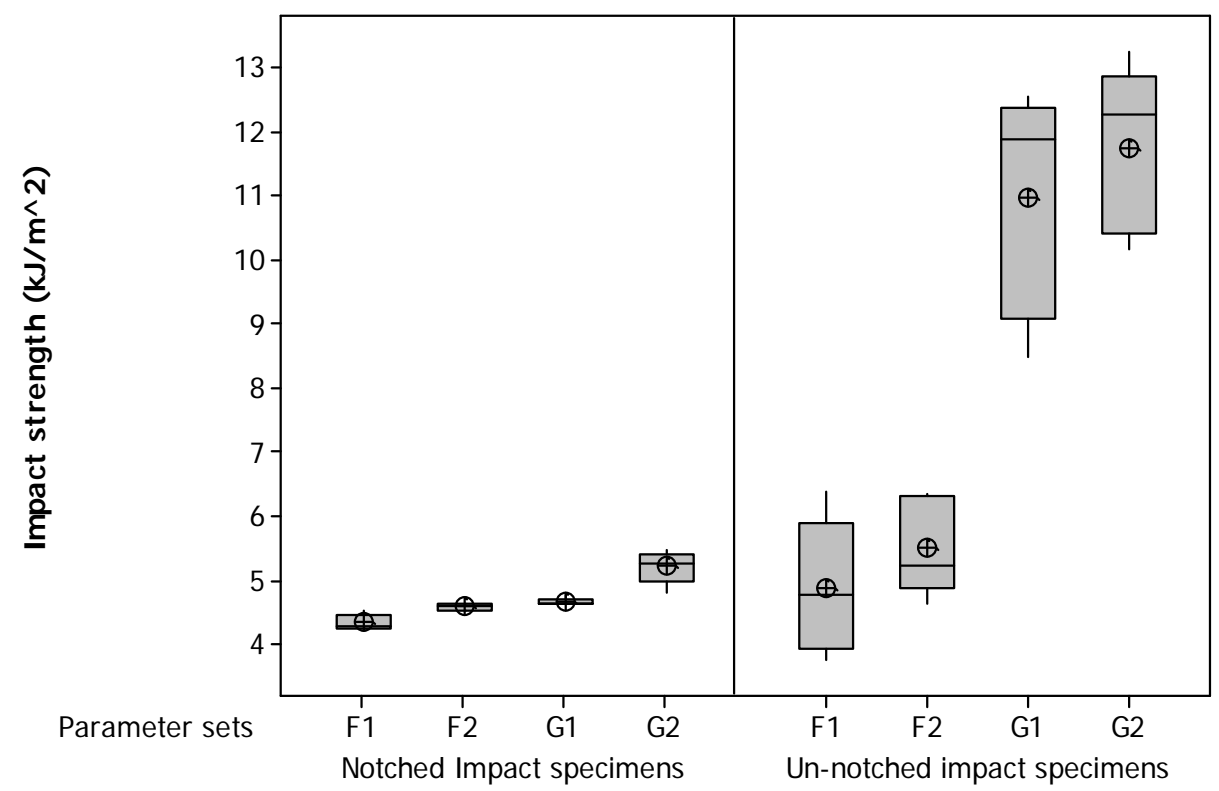

Figure 10 Variation of impact strength with parameter sets, showing the mean, median, lower and upper limits, first and third quartile. $\mathrm{Z}$ oriented parts. 


\subsection{Influence of Build Parameters on Modulus}

Figure 11 shows the variation of flexural and tensile modulus with the parameter set. $\mathrm{G}$ samples generally have higher average stiffnesses that F samples and 2 samples are generally stiffer than 1 samples, with the differences mostly not significant at a 95\% confidence level. A significant difference is only observed between the modulus of F1 and F2 of flexural specimens.

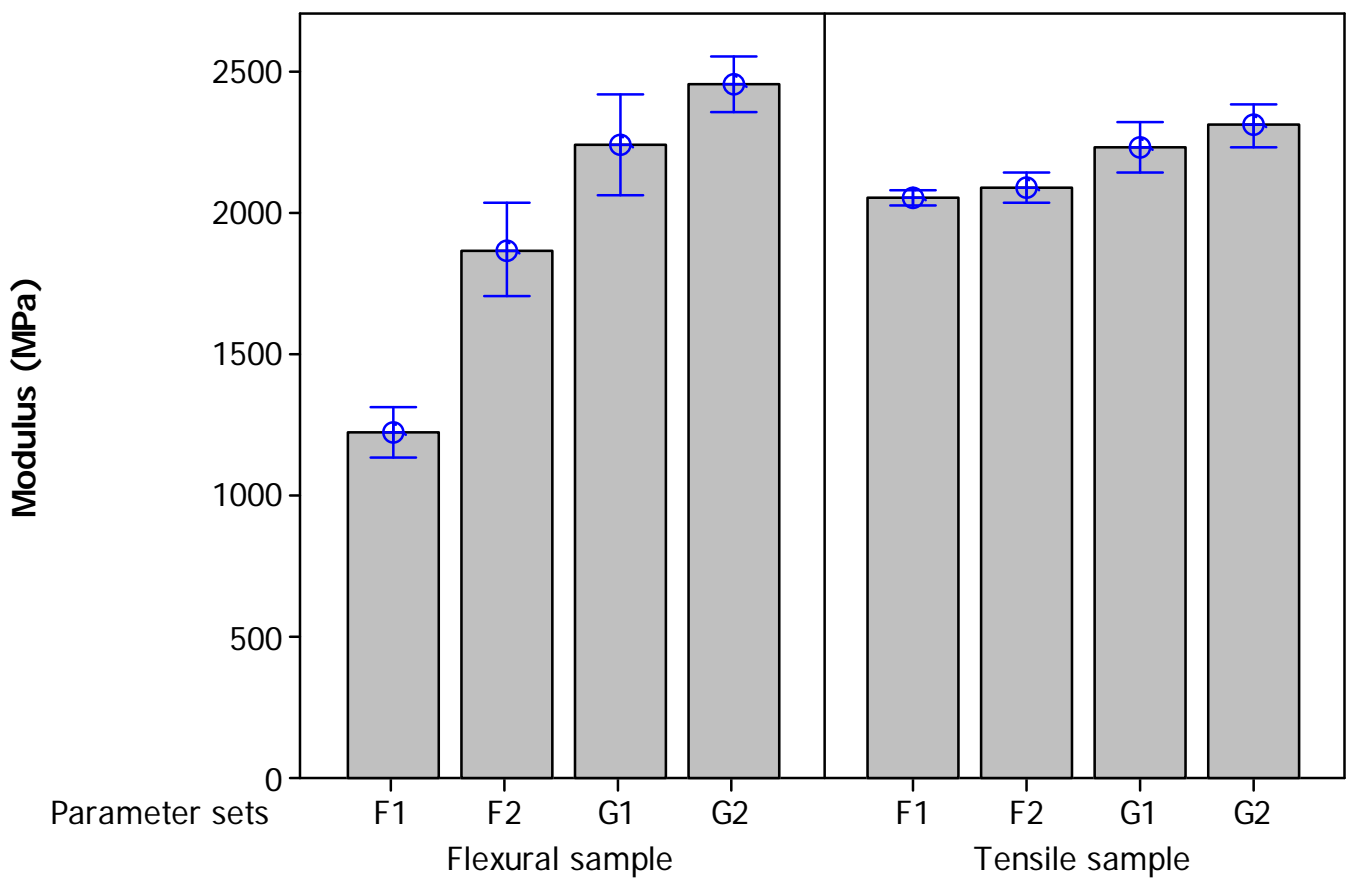

Figure 11 (a) Variation of flexural and tensile modulus with parameter sets. Errors bars indicate $95 \%$ confidence intervals, $n=5$.

\subsection{Fracture Surfaces}

Figure 12 shows fracture surface micrographs of impact specimen. It can be observed that the specimen fails due to porosity between layers and by rupturing of roads. 


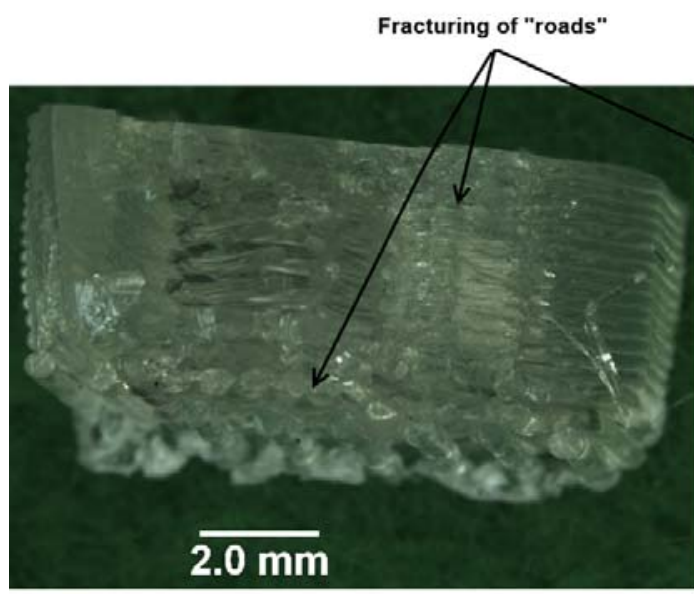

(a) X-oriented specimen Fracture occurs at the interlayer interface

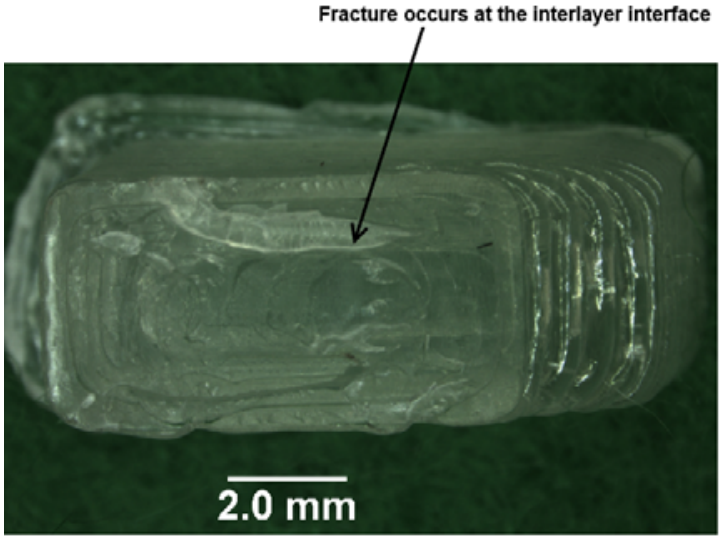

(c) Z-oriented specimen

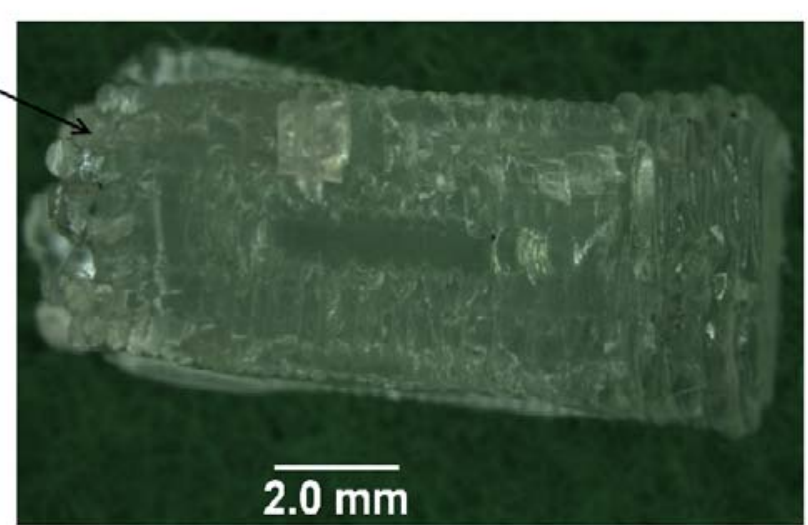

(b) Y-oriented specimen

\section{$2.0 \mathrm{~mm}$}

Figure 12 Fracture surface of impact specimens with their build orientations. All parts made with process parameter set $\mathrm{G} 1$.

\subsection{Discussions}

\subsubsection{Variation of mechanical properties with build orientations}

Figure 5 confirms that the tensile, flexural and impact strengths of the test parts vary significantly $(\mathrm{p}<0.01)$ with build orientation. This agrees with other studies of FFF (Bellini and Güçeri, 2003; Sood et al., 2010; Es-Said et al., 2000; Sophia et al., 2015). We consider that any evaluation of the mechanical properties of parts made using FFF which wishes to consider the worst case must include testing of Z-oriented parts.

\subsubsection{Variation of mass with parameter sets}

The results shown in Figure 6 and Figure 7 can be explained by the following. The increased average mass of the $\mathrm{G}$ samples over equivalent $\mathrm{F}$ samples can be explained by the lower layer thickness of G samples, which results in less porosity. The increased average mass of 2 samples over 1 samples is as a result of the different build strategies outlined in Figure 4, which means that 2 samples contain more material. 


\subsubsection{Variation of Z-oriented specimens Mechanical Properties with Parameter Sets}

From Figure 9 to Figure 11, it can be observed that strengths and modulus of specimens made with process parameter sets F2 and G2 are higher than that of specimens made with parameter sets F1 and G1. As the trend follows that of sample mass shown in Figure 6 and Figure 7, Figure 13 to Figure 15 show the same data, but on the basis of specific properties. When expressed in this way the tensile moduli and notched impact strengths for all parameter sets do not vary to the same extent, with the tensile moduli showing no significant difference, and only the G1 specimens showing a small difference in notched impact strengths from the other parameter sets. For the other strength measures and for the flexural modulus the degree of variation is reduced but the trends are broadly unchanged. For the flexural strength and modulus values, this may be related to the second moment of area effects in bending, and for both the tensile and flexural strengths the size and distribution of flaws will have some influence. The un-notched impact strength seems to be significantly influenced by layer thickness. The role of the notch in the notched impact test is to focus crack initiation in a particular area, and it seems that when this causes inter-layer debonding, even for parts with different layer thicknesses, to occur in a consistent manner.

(a)

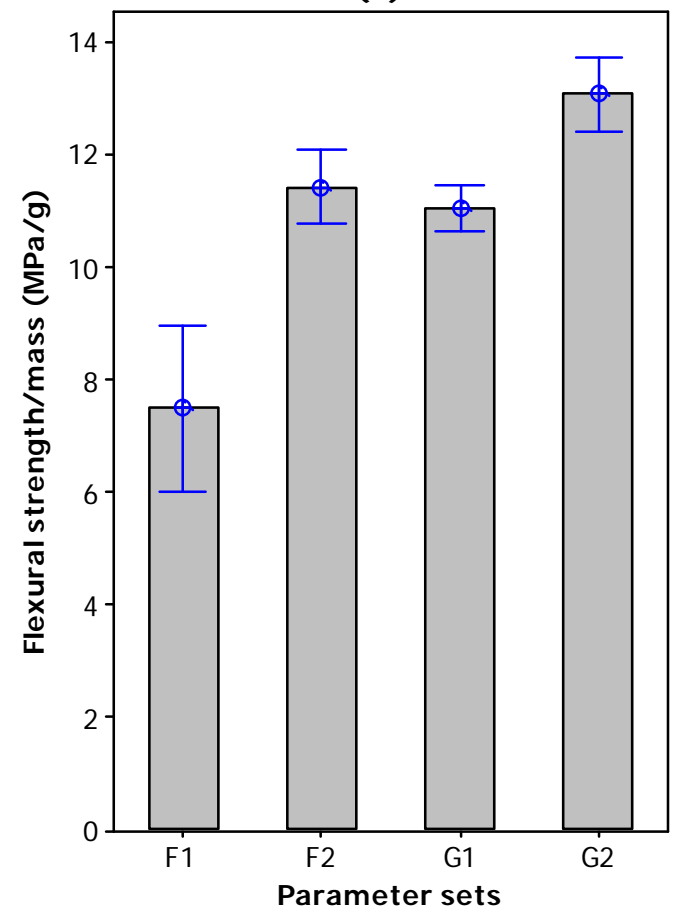

(b)

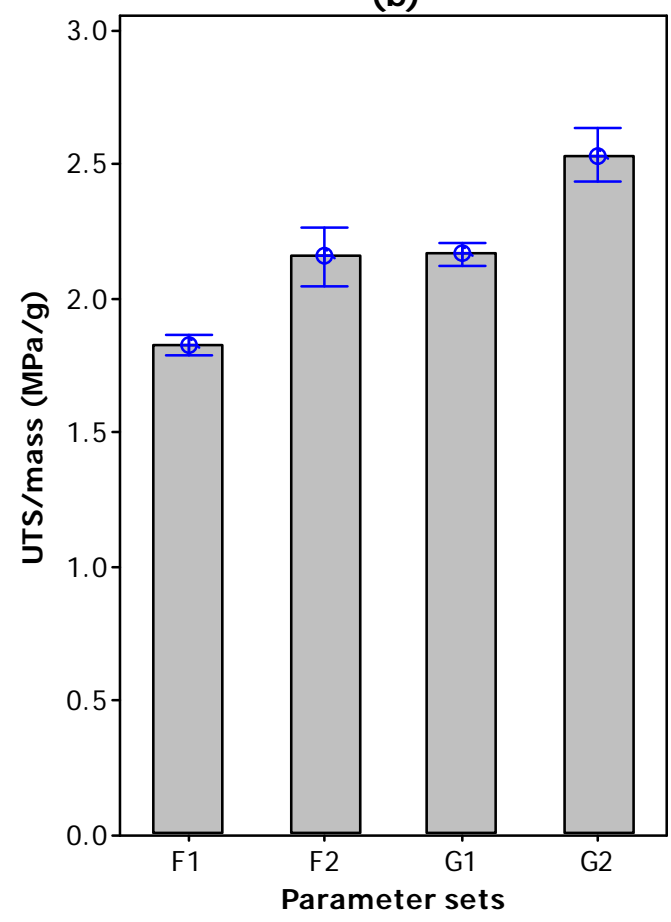

Figure 13 Variation of (a) specific flexural strengths; (b) specific tensile strengths with parameter sets; Errors bars indicate 95\% confidence intervals, $n=5$. 


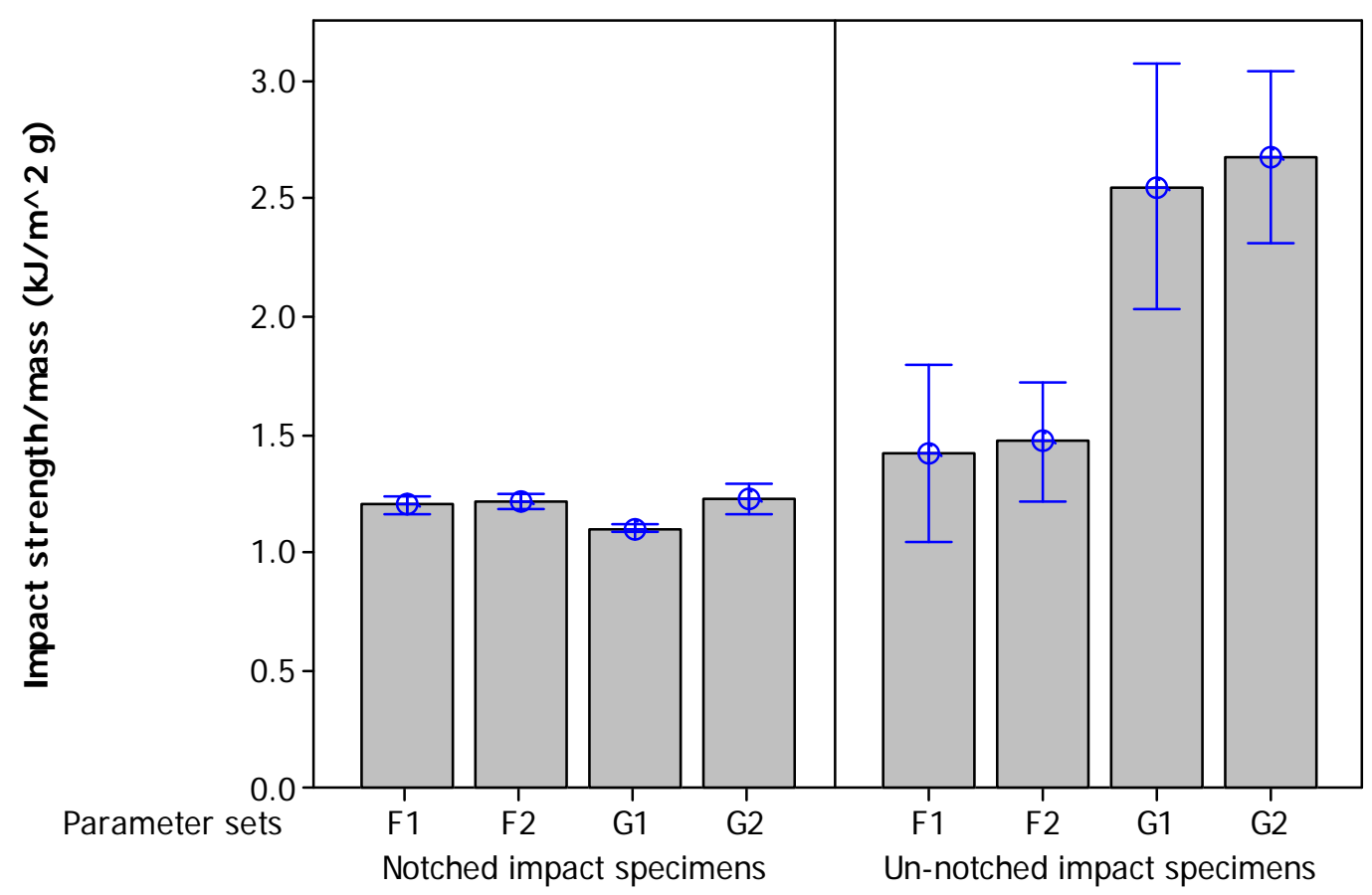

Figure 14 Variation of specific notched and un-notched impact strengths with parameter sets; Errors bars indicate 95\% confidence intervals, $\mathrm{n}=5$.
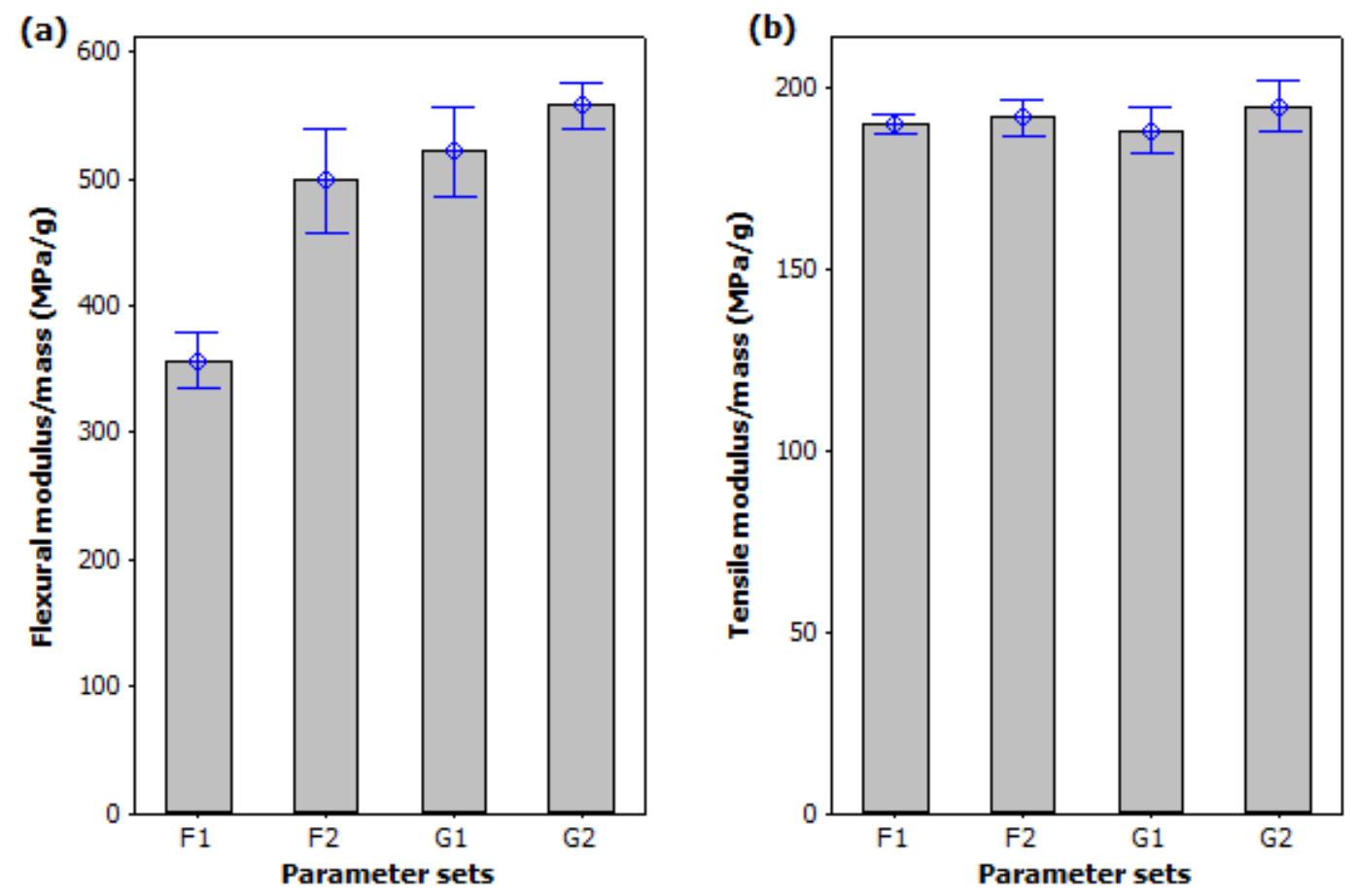

Figure 15 Variation of specific (a) flexural; (b) tensile modulus with parameter sets, Errors bars indicate $95 \%$ confidence intervals, $n=5$. 


\subsubsection{Selection of tests and specimen type for QA purposes}

Tests for quality assurance purposes are not required to assess material properties per se, they need to provide a clearly actionable measure which for practical reasons should be as broadly applicable as possible. In terms of the tests evaluated, the test which is considered to give the clearest view of whether or not a build has been successful is the notched impact test, as illustrated by Figures 10 and 15. This gives a measure which, within the constraints of the study presented here, is largely independent of the process parameters, giving a test which can be used routinely to track machine performance. Impact testing is also quick and relatively low cost. On the basis of the results of this study we would propose that a Zoriented notched impact test specimens, as illustrated in Figure 3, would be an appropriate test specimen for routine QA testing to qualify parts manufactured using an FFF system, with the impact strength, dimensions and weight recorded and used within a statistical process control framework.

\subsection{Conclusions}

- The mechanical properties of parts made using FFF are anisotropic, with the poorest properties along the $\mathrm{Z}$ orientation.

- Notched impact testing of parts built in the Z-orientation offers a test method which, within the constraints of this study, is independent of process parameters. This then offers a convenient test with which to track machine performance over time, as in principle the same test and control limits can be applied across builds with different layer thicknesses and speeds.

References

AGARWALA, M. K., JAMALABAD, V. R., LANGRANA, N. A., SAFARI, A., WHALEN, P. J. \& DANFORTH, S. C. (1996), "Structural quality of parts processed by fused deposition", Rapid Prototyping Journal, Vol. 2, pp. 4-19.

AHN, S. H., MONTERO, M., ODELL, D., ROUNDY, S. \& WRIGHT, P. K. (2002), “Anisotropic material properties of fused deposition modeling ABS", Rapid Prototyping Journal, Vol. 8, pp. 248257.

ANG, K. C., LEONG, K. F., CHUA, C. K. \& CHANDRASEKARAN, M. (2006), "Investigation of the mechanical properties and porosity relationships in fused deposition modelling-fabricated porous structures", Rapid Prototyping Journal, Vol. 12, pp. 100-105.

ANITHA, R., ARUNACHALAM, S. \& RADHAKRISHNAN, P. (2001), "Critical parameters influencing the quality of prototypes in fused deposition modelling", Journal of Materials Processing Technology, Vol. 118, pp. 385-388. 
BAGSIK, A., SCHOEPPNER, V. \& KLEMP, E. (2010), "FDM Part Quality Manufactured with Ultem* 9085", 14th International Scientific Conference on Polymeric Materials, September 15-17 Halle (Saale) Martin-Luther-University, Germany.

BELLINI, A. \& GÜÇERI, S. (2003), "Mechanical characterization of parts fabricated using fused deposition modeling", Rapid Prototyping Journal, Vol. 9, pp. 252-264.

BS EN ISO 178:2010 (2010), Plastics - Determination of flexural properties, European Standards, International Organization for Standardization, Switzerland.

BS EN ISO 180:2001 (2001) Plastics - Determination of Izod impact strength, European Standards, International Organization for Standardization, Switzerland.

BS EN ISO 527-1:1996 (1996) Plastics - Determination of tensile properties, European Standards, International Organization for Standardization, Switzerland.

CHANG, D. Y. \& HUANG, B. H. (2011), "Studies on profile error and extruding aperture for the RP parts using the fused deposition modeling process", International Journal of Advanced Manufacturing Technology, Vol. 53, pp. 1027-1037.

EQUBAL, A., SOOD, A. K., TOPPO, V., OHDAR, R. K. \& MAHAPATRA, S. S. (2010), "Prediction and analysis of sliding wear performance of fused deposition modelling-processed ABS plastic parts", Proceedings of the Institution of Mechanical Engineers, Part J: Journal of Engineering Tribology, Vol. 224, pp. 1261-1271.

ES-SAID, O. S., FOYOS, J., NOORANI, R., MENDELSON, M., MARLOTH, R. \& PREGGER, B. A. (2000), "Effect of layer orientation on mechanical properties of rapid prototyped samples", Materials and Manufacturing Processes, Vol. 15, pp. 107-122.

LEE, B. H., ABDULLAH, J. \& KHAN, Z. A. (2005), "Optimization of rapid prototyping parameters for production of flexible ABS object", Journal of Materials Processing Technology, Vol.169, pp. 54-61.

LEVY, G. N., SCHINDEL, R. \& KRUTH, J. P. (2003), "Rapid manufacturing and rapid tooling with layer manufacturing (LM) technologies, state of the art and future perspectives", CIRP Annals Manufacturing Technology, Vol. 52, pp. 589-609.

MASOOD, S. H., MAU, K. \& SONG, W. Q. (2010), "Tensile Properties of Processed FDM Polycarbonate Material", Materials Science Forum, Vol. 654-656, pp. 2556-2559.

MUNGUIA, J., AKANDE, S. \& DALGARNO, K. W. (2014), “Compliant flexural behaviour in laser sintered nylon structures: Experimental test and Finite Element Analysis - correlation", Materials \& Design, Vol.54, pp. 652-659.

PANDEY, P. M., REDDY, N. V. \& DHANDE, S. G. (2003a), "Real time adaptive slicing for fused deposition modelling", International Journal of Machine Tools and Manufacture, Vol. 43, pp. 61-71.

PANDEY, P. M., VENKATA REDDY, N. \& DHANDE, S. G. (2003b), "Improvement of surface finish by staircase machining in fused deposition modeling", Journal of Materials Processing Technology, Vol. 132, pp. 323-331.

PENG, A., XIAO, X. \& YUE, R. (2014), "Process parameter optimization for fused deposition modeling using response surface methodology combined with fuzzy inference system", The International Journal of Advanced Manufacturing Technology, Vol. 73, pp. 87-100.

QIU, D. \& LANGRANA, N. A. (2002), "Void eliminating toolpath for extrusion-based multi-material layered manufacturing", Rapid Prototyping Journal, Vol.8, pp. 38-45.

QIU, D., LANGRANA, N. A., DANFORTH, S. C., SAFARI, A. \& JAFARI, M. (2001), "Intelligent toolpath for extrusion-based LM process", Rapid Prototyping Journal, Vol. 7, pp. 18-24.

ROSOCHOWSKI, A. \& MATUSZAK, A. (2000), "Rapid tooling - the state of art", Journal of Materials Processing Technology, Vol. 106, pp. 191 - 198.

SOOD, A. K., OHDAR, R. K. \& MAHAPATRA, S. S. (2009), "Improving dimensional accuracy of Fused Deposition Modelling processed part using grey Taguchi method", Materials \& Design, Vol. 30, pp. 4243-4252. 
SOOD, A. K., OHDAR, R. K. \& MAHAPATRA, S. S. (2010), "Parametric appraisal of mechanical property of fused deposition modelling processed parts", Materials \& Design, Vol.31, pp. 287-295.

SOPHIA, Z., MARYVIVIAN, O. \& CONSTANCE WILKENS, Z. (2015), "Tensile and fatigue behavior of layered acrylonitrile butadiene styrene", Rapid Prototyping Journal, Vol. 21, pp. 270-278.

SUN, Q., RIZVI, G. M., BELLEHUMEUR, C. T. \& GU, P. (2008), "Effect of processing conditions on the bonding quality of FDM polymer filaments", Rapid Prototyping Journal, Vol. 14, pp. 72-80.

VASUdEVARAO, B., NATARAJAN, D. P., HENDERSON, M. \& RAZDAN, A. (2000), "Sensitivity of RP surface finish to process parameter variation", Proceedings of the Solid Freeform Fabrication Symposium, The University of Texas at Austin, Austin, TX, pp. 251-258.

ZHANG, Y. \& CHOU, Y. K. (2006), "Three-dimensional finite element analysis simulations of the fused deposition modelling process", Proceedings of the Institution of Mechanical Engineers, Part B: Journal of Engineering Manufacture, Vol. 220, pp. 1663-1671. 